\title{
ACCESSIBILITY ASSESSMENT: TRAINING THE SLUM RESIDENTS IN SCALING THE 'ACCESSIBILITY'
}

\author{
Aparna Phadke* \\ Department of Geography, University of Mumbai, India - aparna.phadke@geography.mu.ac.in
}

Commission V, WG V/7

KEY WORDS: Informal, habitat planning, dualism, Accessibility, ODK, smart, Quantum GIS

\begin{abstract}
:
With almost half of the developing world turning 'urban', it becomes a major challenge for the local self-governments to assure availability and accessibility of basic infrastructural facilities to citizens at affordable rates. The issues of accessibility become especially complicated in the cities of Global South as 'accessibility' is highly politicized and governed by various forces that shape social, cultural and economic hierarchies. The city space not only experiences spatial segregation but also a peculiarly linked social segregation that runs along ethnic identities creating conditions of social and economic polarization at not only macro level as well as at micro levels within slums that house lower income groups (LIG) and economically weaker sections (EWS). The conditions of inaccessibility decisively affect the wellbeing of these groups leading to erosion of social and mental wellbeing. The effective implementation of various welfare schemes also mostly remains inadequate due to the highly complicated nature of 'inaccessibility' and lack of transparency.
\end{abstract}

For effective implementation of various welfare schemes, the government has already moved towards 'e-governance'. Ironically, the use of 'smart' technology remains restricted to higher income groups and the LIG and EWS gets excluded again due to lack of knowledge. In fact, these sections of urban population who suffer absolutely due to conditions of 'inaccessibility' need to be trained and involved in measuring the levels of accessibility and improving access to various basic infrastructural facilities. The paper will attempt at introducing a module that is based in simpler technologies like ODK (open data kit) and Quantum GIS to train the slum residents in mapping the accessibility vis-à-vis basic infrastructural facilities and improve the accessibility through positive deliberations with the local selfgovernments.

\section{INTRODUCTION}

If one attempts at defining accessibility in simple text, it could be the quality of being able to be reached or entered or obtained easily (Cambridge Dictionary). Accessibility also could be approachability and a quality of being available when needed. Interestingly, the very 'quality of being available' is defined by various factors and conditioned by not only socio-economic and political situations but also governed by spatio-temporal aspects. To elaborate further, accessibility is strongly rooted in spatial structures and social relations of production (Harvey, 1990). In a way, geography decides availability of resources primarily as per the specific compositions of natural elements available therein. But such accessibility is conditioned by nature's diversity. If diversity is nature made, then there should be equal access to all but in man-made system, 'access' has various socio-political and economic dimensions. 'Access' also has the spatio-temporal context in terms of level of 'development'. Ideally, due to diversity in resource base, human skills, and social relations of production, different spaces would experience structuring of 'access' differentially and the social structures would continue to transform themselves to also transform the very nature of 'access'. Ironically, the spatial systems that have been structured so far are

${ }^{*}$ Corresponding author not merely different from each other; these are nested in a power hierarchy that governs the conditions of accessibility leading to disparities rather than differences. How the circuits of production, consumption and distribution are organized in space? How resources and wealth are distributed? In the process who gets benefitted? Finally, how spaces are socially and culturally structured are key questions in governing the accessibility as it decides how an individual will be placed in a particular Socioeconomic, political and spatial milieu and what 'things' will be accessible to him at individual, family and societal levels.

The structuring of 'accessibility' gets complicated in India with uneven pattern of spatial development. In spite of various planning and policy efforts, the conditions of spatial imbalance continued to remain prominent, structuring stark incidences of spatio-social and economic polarisation. Further deepening of the economic and social stratification is witnessed in era of implementation of New Economic Policy (NEP) with recentralisation and urbanisation of finance capital. Ironically, the structuring of 'accessibility' gets further complicated with the 'politicisation' based into ethnic and class identities. All these factors collectively shape the very process of infrastructure development and provision. The accessibility becomes explicit spatially creating spaces with stark variations in terms of availability, accessibility and approachability of basic infrastructural facilities. Particularly when it comes to basic service provisions to slums, squatters and other 'degraded' forms of residential space, there has been a huge compromise on the part 
of state in provision. The same is justified by 'terming' these spaces as illegal, illegitimate and so on. At this backdrop, the role of finance capital as a major element in shaping urban built environment should be analysed. The same should be associated with the escalated demand for urban land for various development projects and the huge lands occupied by slums that could be recycled to reproduce residential and commercial space. The same could be considered as a part of pressure that the slum areas are facing primarily. Secondly, there have been urban regeneration efforts that have allowed densification of urban spaces through upgradation of various urban land ceiling acts, opening of various urban lands like mill lands and increased FSI to create more office and residential spaces. The slums that have occupied strategic locations in cities thus become immensely important for capital markets as the redevelopment of the land occupied by slum would bring huge profits. Thirdly, a major share of urban land is now getting consumed for mega transport projects that are largely planned through the patches occupied by the lower income and economically weaker sections within the cities, inducing huge displacement of slum dwellers towards peripheral slums leading to further deteriorating living conditions. That suggests that the slums are facing huge pressure and remain compromised in every sense - whether it is civic infrastructure or basic standard of living.

When on the one hand, the transformation in the urban space is responsible for complicating the conditions of urban accessibility as there has been increasing spatial and social polarisation of urban poor, on the other hand there has been a strong sentiment of 'payable access' not only by the state but also by the taxpayers. Secondly, the 'access' has been more and more under vigilance and to do so there has been installations of various digital technologies right from Aadhar- Unique Identification Number to e-governance. The introduction of digital technologies into governance has brought in new complexities and challenges as technological and digital literacy among people has remained a major issue. The National e-Governance Plan (NeGP) was launched in 2006 with a vision to make all government services accessible to the common man in his locality, through common service delivery outlets and ensure efficiency, transparency \& reliability of such services at affordable costs to realize the basic needs of the common man (http://negd.gov.in/digital-india). 31 Mission Mode Projects covering a wide range of domains, viz. agriculture, land records, health, education, passports, police, courts, municipalities, commercial taxes, treasuries, etc. were initiated. Most of these projects have been made operational and have started providing services (http://negd.gov.in/digital-india). For example, National Remote Sensing Centre has developed various mobile based application and trained the government officers to survey progression of various social welfare schemes like MNREGA(National Employment Mission), road constructions, etc. However, the digital technologies have been again mastered by the upper class though use of smart phones has been prevalent across various socio-economic classes. Despite the successful implementation of many e-governance projects across the country, e-governance as a whole has not been able to make the desired impact and fulfil all its objectives especially in ensuring anytime anywhere availability of services and their seamless integration. Even though India is known worldwide as a powerhouse of software, the availability of electronic government services to citizens is still comparatively low (http://negd.gov.in/digital-india). There is a general belief that the use of smart phone could be considered as technological tool but it definitely cannot be considered as digital literacy as the digital literacy involves much deeper degree of technological, technical skills and knowledge. Thus e-governance also becomes domain of upper class and remains out of reach of lower income and economically weaker groups. The same introduces another dimension to already existing forms of exclusion.

Slums are defined as the most highly dense, low-rise, substandard, and unhealthy environments suggesting, absolutely compromised state of civic facilities. Supreme Court of India has already passed a judgement making it mandatory for the state to provide water to all the squatters and slums irrespective of their legal or illegal status (Thieme \& Kovacs, 2015). One of the four biggest slums in Mumbai is situated in Mankhurd-Govandi-Deonar area.

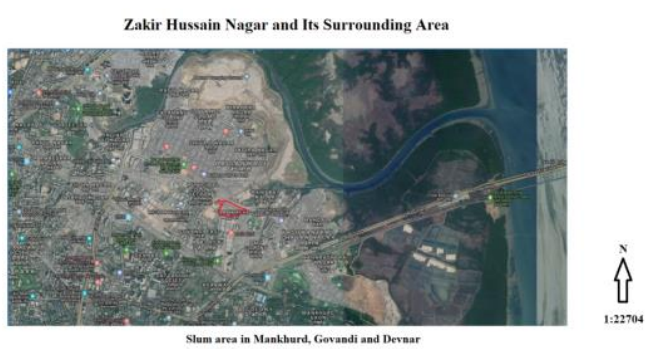

Figure 1 : The Study Area and Surrounding Region Source : Google Earth

The slum is situated at the outskirts of BrihanMumbai Municipal Corporation. The provision of basic civic facilities is highly compromised. With densification and horizontal expansion of slum, there have been increasing incidences of polarisation and conflicts among the dwellers and municipality. The slum area has also faced demolitions and is under constant threat due to its location. Major mega-transport projects are planned through this area to connect New Mumbai with BrihanMumbai leading to constant fear of slum removal and displacement of people. There has been hardly any dialogue between the slum dwellers and government and municipal authorities as there is absolute lack of trust. The same leads to display of anger and outrage by slum dwellers vis-à-vis any official coming for any kind of survey of land. It was conceived that if there has to be improvement in the basic civic facilities, and if the municipality is moving towards 'smart' digital governance, then whether the slum residents can be trained to assess status of accessibility of basic services through their mobile phones using ODK. The researcher trained one of the girls who is a resident of Shivajinagar slum to undertake survey through ODK.

\subsection{OBJECTIVES}

Following the above discussion the objectives of the present research are set to be -1) understanding the process of structuring the patterns of 'accessibility' with special reference to urban poor and suburban slums, 2) application of Open Data Kit (ODK) in collecting spatial data regarding accessibility with reference to potable water and sanitation, 3) Understanding the response of slum dwellers with reference to use of easy technology like ODK to map the accessibility 4) Training the slum residents to collect 
data regarding accessibility, 5) analysing the spatiality of 'accessibility' with the help of QGIS

\subsection{STUDY AREA}

The research aims at promoting application of user friendly technologies like ODK in accessing real time information about accessibility; empowering the slum dwellers by training them to use the modern technology in community management and everyday governance and promote a participatory citizenship in managing civic facilities. For the very purpose, Zakir Hussain Nagar, Govandi, M-East ward, Mumbai is selected. The study area belongs to one of the biggest slums in Mumbai, even bigger than Dharavi, extended in Mankhurd, Devnar and Govandi. In terms of accessibility, this particular area becomes immensely important as there has been a severe crunch of basic civic facilities.

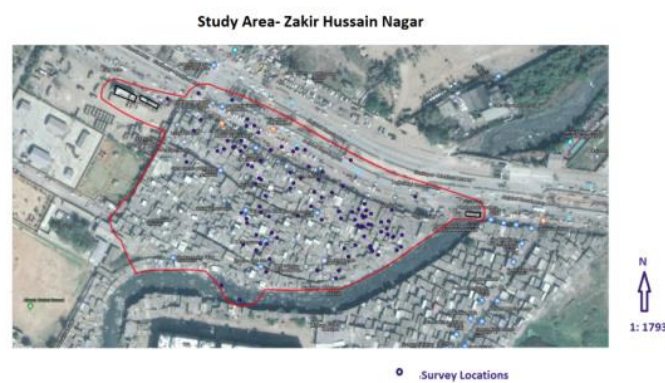

Figure $2:$ The Study area and surveyed locations Source : Google Earth and ODK Build in QGIS

The area is continuously expanding vertically and horizontally with newer migrants getting shelter; rehabilitation of displaced people from the other demolished slums and natural population growth. The area has also been facing demolition and acquisition of land for various mega urban development projects. The big companies like reliance have acquired the adjacent lands and they continue to bother these slum residents by obstructing access to many vital services and free mobility. The slum residents are basically from Uttar Pradesh and Bihar and mostly Muslims along with some other backward caste people. In a way, the area emerges to be a ghetto of Muslim population. The area is bound by Mithi River on the one side and flyover and express highway connecting New Mumbai and Mumbai on the other side. There have been many informal economic activities like, rag picking, tailoring, domestic servants, sweepers and so on through which the residents make their living. The researcher selected one girl named Anjum for the training purpose who has been living there for more than 15 years. She was trained to use ODK to collect data on water and sanitation accessibility in Zakir Hussain Nagar. The data collected was specific to water and sanitation. This research is a part of deeper research that is taken up. The researcher is also planning to develop links with BrihanMumbai Municipality and the assistant commissioners of M-East ward for further collaboration where the data collected by slum residents can be considered as a real time data for any future planning and policy interventions.

\subsection{RESEARCH METHODOLOGY AND DATA COLLECTION}

The data has been collected largely through primary sources of information. A questionnaire survey has been conducted using ODK mobile app. Then the data is transferred to GIS environment through Quantum GIS and then the analysis is done. Use of ODK has facilitated to combine the quantitative data and its technical aspects to ethnographic survey (qualitative research). In all, 106 samples have been collected in Zakir Hussian Nagar. The samples have been spread all over Zakir Hussain Nagar excluding the South-West corner of the area. People staying in this area rejected any interview as they were frustrated with researchers, various NGOs and government authorities who continued to have rounds of interviews with them and did nothing. It is the stratified sampling method that has been used to collect samples in a spatially distributed manner. The research assistant has been resident of the same area who was selected for training to collect information regarding water and sanitation. It is the inductive research logic that has been applied. Interpretive and critical research approaches have been applied to analyse the situation.

\section{SCALING THE ACCESSIBILITY IN ZAKIR HUSSAIN NAGAR}

It could be revealed through the census data as well that the population growth rate of South Mumbai has decreased substantially and increased in Mumbai suburban and inner periphery. The same is also associated with commercialisation of economic base of Mumbai. Following which there has been reproduction of space of housing advanced economic activities and their subsidiaries (Sassen, 1991) and upper class residences. With increasing commercialisation of land assets, there has been simultaneous shrinking of urban space for urban poor leading to increasing peripheralisation. Mankhurd being the boundary of BrihanMumbai thus experiences slumification as a result quantitative migration and expulsion of urban poor from the already existing slums in the mother city of South Mumbai in name of redevelopment, environmental protection and infrastructure development. This particular slum perhaps is one of the biggest slums with the most vulnerable conditions vis-à-vis everyday life. The slum has legal and illegal connotations regarding the land and house ownership but the space allows some thousands of poor people to have shelter. It is found that these are public stand posts supplied by the BMC for the provision of water. Water is supplied only once in a day that too in 70 percent of locations, it is in the evening and 30 percent of locations it is in the afternoon. One public stand post is shared by at least 15 to 20 families. In rare cases where the residents belong to better income group and essentially has good political back up tends to get individual connections, many a times illegally. The quality of water is reported to be moderate to worst and the duration of water supply on an average is hardly for 2 hours. In certain few locations, it was observed to be above two hours. Seasonal variation has been observed in all three seasons in terms of quantity, quality and time duration. Summer season is most difficult as there is always a water shortage. The uncertainty in water supply leads to water storage. It is observed that 100 percent of samples had opted for water storage facilities. The same is indicative of compromised water supply situation in the area. The worst quality of water has also compelled the slum 
dwellers to go for various water treatment measures including boiling of water, purifying the water through traditional methods, etc. But for more than half slum dwellers, the water treatment is not affordable and they continue to drink water without any treatment. Only in one case, it was reported to have the modern water purifier like Aqua guard. The worst quality of water is also responsible for various epidemics like Cholera, gastro, etc. The public stand posts serve the houses mostly within 500 metres distance.

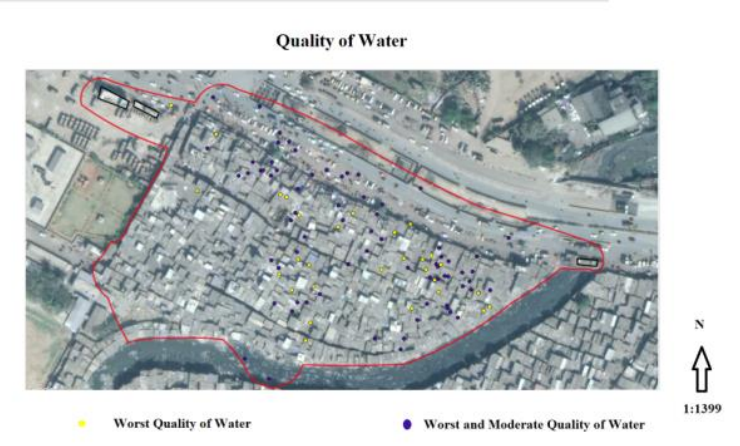

Figure 3 : Status of Water Provision Source : Questionnaire Survey

Provision of sanitation facilities have remained a major issue in slums due to its compact and crowded nature. Provision of gutters is one of the basic facilities but in Zakir Hussain Nagar, in almost 70 percent locations gutters are not provided only. The Area is bounded by water streams locally referred as Nallah that is deteriorated form of river due to pollution. In the absence of gutter, the residents have their own ways of dealing with the waste water and it is in absolutely unorganized and shabby forms. No proper system for drainage and sewerage has turned this area into a susceptible area for all kinds of epidemics.

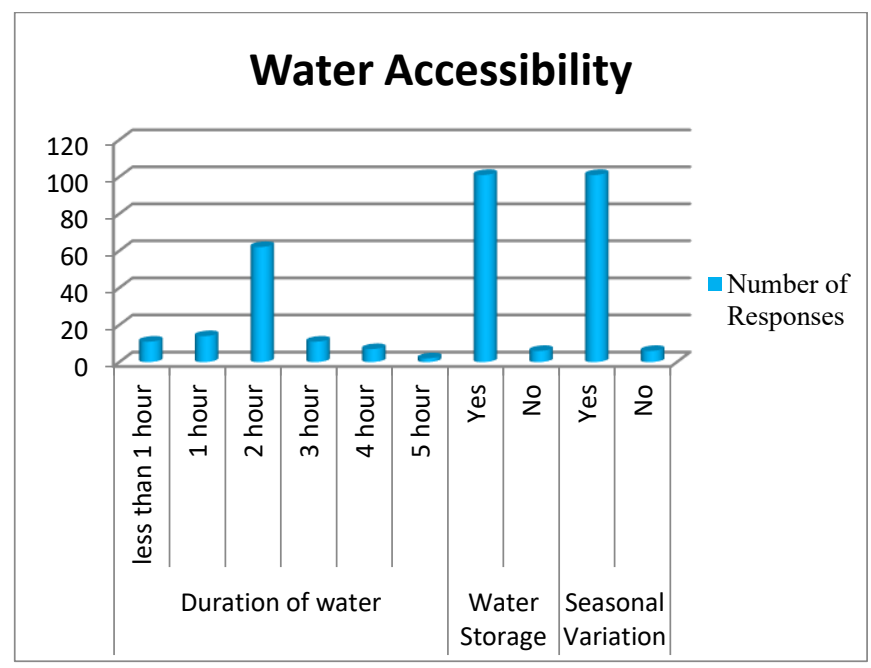

Figure 4: Accessibility and Water
Wherever the gutters are provided, they are not cleaned regularly by BMC causing clogging most of the times. The situation turns grim in rainy season as the clogging causes accumulation of water. There is no proper system of solid waste disposal and it was reported by many that BMC is absolutely irregular in collecting the waste. Interestingly, the Deonar Dumping ground is located few kilometers away from this area and almost 20 percent of slum population is involved in rag picking and recycling activities. In fact, the rag pickers used to collect plastic, metal and other types of recyclable garbage that used to be either dumped in the river by residents in the vicinity or carried away by the running water. With Reliance Company taking over the adjacent land plot, they have fenced and closed the access of these rag pickers to river, rendering them unemployed. Reliance and the slum residents continue to accuse each other for dumping waste in the river. The consequences of the same have been in the form of complaints and closing of access to slum residents to river. It has been also been reported that the same has led towards increasing crime rate in the area.

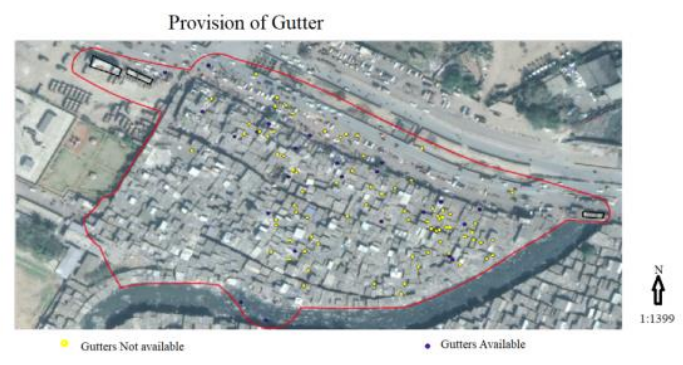

Figure 5: Provision of Gutters

Source : Questionnaire Survey

Across the road, there is SMS Company that treats biomedical waste including human body parts. Some of the slum dwellers also work in this company. The company is said to have contract with Shatabdi and Rajawadi hospital. These slums workers are appointed to segregate the biomedical waste. Ironically, it was reported that the bio-medical waste is given to this company collectively like syringes, needles, operated and removed human body parts like fetus, unborn babies, etc. The slum workers segregate all these into separate bags and then everything is burnt. Mostly, these are women from slum those are employed for segregation work who come from pressing economic and social situations. The smoke that gets generated is reported to be very hazardous and polluting as the height of the chimney is not as per the set environmental standards. The very high levels of air pollution have affected the very health of slum residents. All kinds of respiratory disease including tuberculosis are very common in Zakir Hussain Nagar. Due to uncleanliness, 90 percent of slum residents reported to have mosquitoes. The vector borne diseases like malaria, typhoid, dengue and viral fever are prevalent. Skin diseases like scabies are other such prevailing diseases. In fact, the entire family members were found to have scabies. Toilets are available to all the slum residents in the study area but in the form of public toilets. In all, for the entire slum population of 36 toilet

Source : Questionnaire Survey 


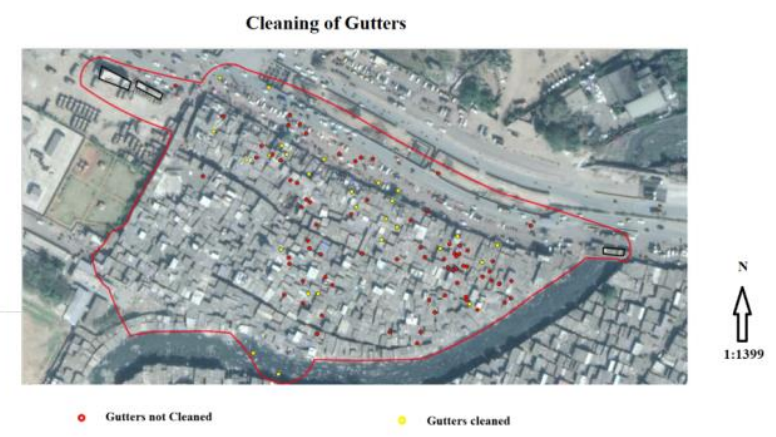

Figure 6: Cleaning of Gutters

\section{Source : Questionnaire Survey}

blocks are available. Out of which 28 toilet blocks are for men and only 8 toilet blocks are meant for women. The toilet blocks are also located on the either ends of the area causing a huge inconvenience to the slum people. Only 16 percent slum residents suggested to have free access to toilets. Out of the remaining, 96 percent of the slum residents pay at least 3 rupees per trip per person to toilets. Some of the interviewees said that the access to toilets is from early morning to 12 o'clock in the afternoon. Then the toilets are closed till next morning. In such situations, then the slum residents don't have any other option than littering the open space. In fact, the small children squatting along the highways have been crushed by the speedy vehicles. Such incidences are very common and happen every other month. The severe crunch of basic civic facilities thus could be assessed by Anjum not only with exact locations but also with precise information. The documentation of such vital data will prove to be essential for the community and various social organisations to pursue these matters with the local self-governments.

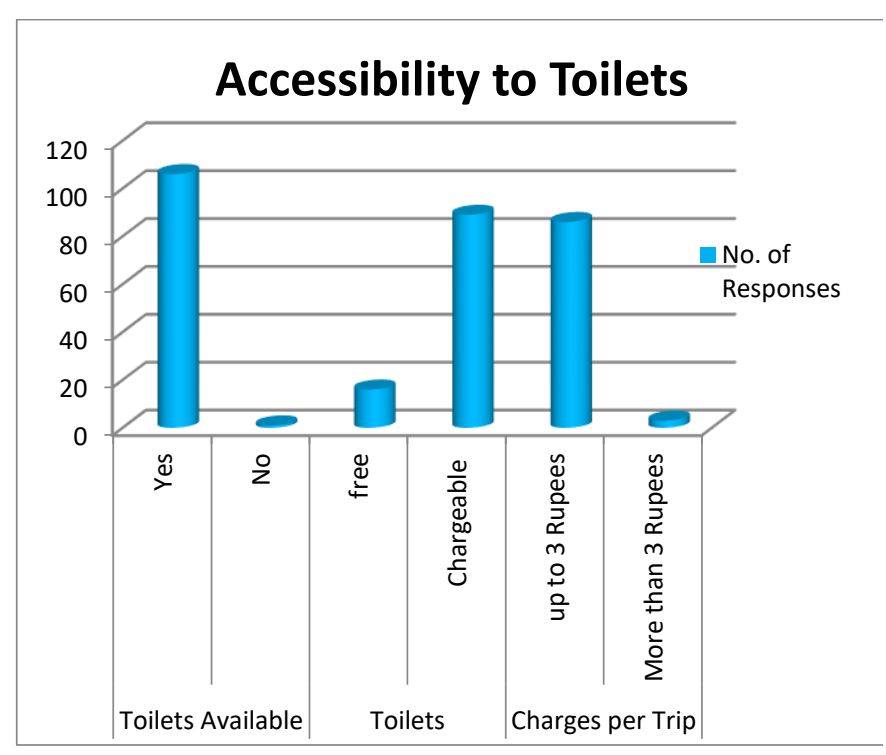

\section{Conclusion}

Zakir Hussain Nagar, must be housing around 5000 to 6000 population. Largely, this population is migrant population coming from lowest economic strata in search of livelihood and better life to Mumbai from Northern Indian states having lower levels of economic development and grim social situations that are deeply rooted in caste system and communal segregation. In fact, there have been stark incidences of polarization of lower caste communities and Muslims in Northern Indian states. To rescue from such depressing economic and social conditions, fleet of the unemployed men following the kinship and lineage relations continue to descend to this area. In Mumbai too they continue as informal labour ending up into lowest strata of social and economic hierarchy. The more rerouting of newer migrants to peripheral slums is another trend that is set for last three decades and responsible for deterioration of peripheral slums as with increasing densification, the already inadequate infrastructural facilities get further divided. Interestingly, the inadequate facilities also become inaccessible, for example, access to public toilets. Though there have been in all 34 toilet blocks, their availability does not get translated into accessibility as these toilets offer paid access. The average monthly income of people here would be ranging from 3000 rupees per month to 20000 and so. That means people with lower income would find the paid access as equal to no access. For example, in a family of five, only for toilets the family has to spent 25 to 30 rupees roughly per day and 750 rupees monthly. Instead, they would prefer squatting and littering openly. The water is available freely but if we calculate, for each family it is available only for 20 minutes. The quality of water is moderate to worst and that is suggests that though water is available freely, it either involves cost for treating the water (boiling, water purifying drops, etc) or the slum residents have to pay for water borne diseases. The same is suggestive of various constraints in having access to clean and safe drinking water, proper sanitary system in the form of solid waste management, gutters, drainage canals and toilet facilities that are freely accessible.

The approach of local governing bodies towards slum is not inclusive. Is it really possible to provide affordable housing to all through current form of private-public participation? Is the government really concerned about providing facilities to slums? Is the set mechanism comprehensive enough to include the poor people. Slums are the spaces created by poor for poor. As fundamental right, they are entitled to get free access to basic facilities like water. In fact, the slums are considered as burden by most of the administrators, planners and upper income groups. They are considered to be the malicious, ragged and pockets of all social evils. The planning mechanisms are also set through similar vision considering slums as 'problems' and insist upon removal of slums rather than including slums in the mainstream developmental flow. Such attitudes continue ignore the problems of slums.

Figure 7 : Access to Toilets

Source : Questionnaire Survey 


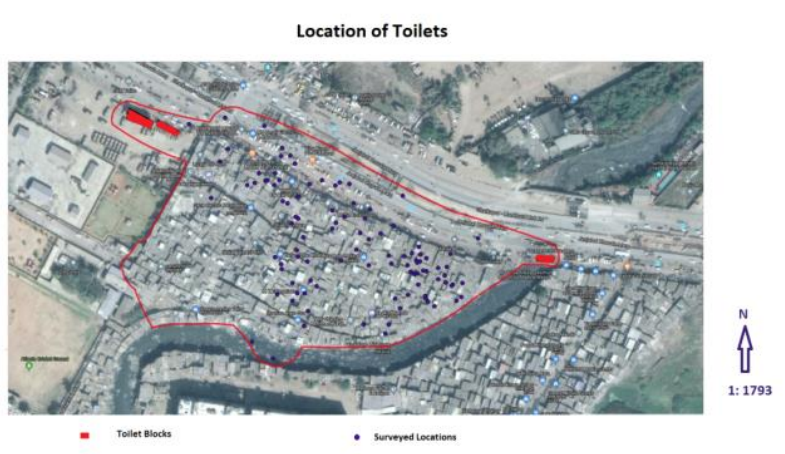

Figure 8 : The location of Toilet Blocks

\section{Source : Questionnaire Survey}

Objective of this research is technological inclusion of EWS and LIG by empowering them with the knowledge and use of modern technology. This has been one of the first attempts of the researcher to work with slum residents and train one of them to conduct a survey that is associated with provision and accessibility to basic civic facilities. The researcher plans to expand the initiatives to entire slum and plan to train and include more slum residents. The entire project will also be discussed with the assistant commissioner of M-east ward and create possibilities of development of a module that can be useful in documenting the detailed information of the infrastructural facilities available within these bigger slums. While doing so, as the slum residents would get involved in identifying the problems precisely, they would emerge responsible for themselves and their community. The present form of e-governance remains very narrow and it is a domain that is absolutely controlled by either government officials or corporate sector and technological tycoons. Let the benefits of modern remote sensing and GIS technologies be extended to them to become part of e-governance. The problem of slums could only be solved with the inclusion of slum communities in planning and designing their own physical and communal spaces.

\section{References}

Yardley, J (2017) : Dharavi: Self-created Special Economic Zone for the Poor, Deccan Herald 17 ${ }^{\text {th }}$ Sept, 2017

Takeuchi, A ; Cropper, M \& Bento, A (2006) : The Welfare Effects of Slum Improvement Programs The Case of Mumbai, World Bank Policy Research Working Paper 3852, February 2006

Thieme, T; Kovacs, E (2015): Services and Slums: Rethinking Infrastructures and Provisioning across the Nexus, Nexus Network think piece Series, Paper 004 (April 2015), Economic \& Social Research Council

Zhang, Y. (2017): Building a Slum-Free Mumbai? State and Informal Urbanization in India, Paper prepared for Conference on the Political Economy of Contemporary India, January 9-10, 2017, Indira Gandhi Institute of Development Research, Mumbai, India. Research presented in the paper is part of the author's book project on informal housing and urban governance in China, India, and Brazil.

Harvey, D. (1985): Urbanisation of Capital: Studies in History and Theory of Capitalist Urbanisation, John Hopkins University Press, New York

Sassen, S. (1991): The Global City: New York, London, Tokyo, Princeton University Press, New Jersey

www.thehansindia.com (2017) : An Analysis on the Role of India's Informal Economy 